http://jmscr.igmpublication.org/home/

ISSN (e)-2347-176x ISSN (p) 2455-0450

crossref DOI: https://dx.doi.org/10.18535/jmscr/v7i7.53

\title{
Posterior Cranial Fossa Space Occupying Lesions in Children: An Institutional Experience at Tertiary Care Center
}

\author{
Authors \\ Saini Sunita ${ }^{1}$, Mathur Kusum ${ }^{2}$, Saini Vikas ${ }^{3}$ \\ ${ }^{1}$ Senior Resident, ${ }^{2}$ Professor, ${ }^{3}$ Resident \\ ${ }^{1,2}$ Department of Pathology, SMS Medical College, Jaipur, Rajasthan \\ ${ }^{3}$ Department of PSM, SMS Medical College, Jaipur Rajasthan \\ *Corresponding Author \\ Saini Vikas \\ Resident, Department of PSM, SMS Medical College, Jaipur Rajasthan, India
}

\begin{abstract}
Abstarct
Background: Tumors in the Posterior cranial fossa are well known for their critical location and complications like brain stem compression and hydrocephalus. This study was conducted to analyze the histological types, frequency of the posterior cranial fossa tumors in children at SMS medical collage Jaipur, Rajasthan.
\end{abstract}

Aims and Objectives: To find incidence and histomorphological pattern of posterior cranial fossa lesion in children; at our tertiary care center.

Material and Methods: It was a retrospective study in which 66 consecutive cases of posterior cranial fossa tumors in children are studies from January 2017 to May 2019.

Results: Among 66 cases, 42 male and 24 female patients with male predominance.The morphological distribution of posterior cranial fossa lesion was as follows:- 25 cases Medulloblastoma, 21Pilocytic astrocytoma, 3 cases of each ependymomas and Epidermoid cyst, 2 cases of each Meningioma, Glioblastoma WHO grade 4 and abscess each, 1 case of eachSchwannoma,A-V malformation, arachnoid cyst,choroid plexus papilloma, TB, ependymal cyst, AT/RT and colloid cyst.

Conclusion: Medulloblastoma and pilocytic astrocytoma are commonesttumor in pediatric age group with male predominance.

Keywords: Posterior cranial fossa, pediatric, medulloblastoma, pilocytic astrocytoma.

\section{Introduction}

Brain tumor is most of fatal tumors, especially in the posterior cranial fossa because of limited space. These posterior fossa tumors are considered critical because they cause brainstem compression, herniation and death. ${ }^{1-3}$.

The clinical presentation depends on the site of the tumor, biological behavior and aggressiveness of the tumor and the rate of growth. The patient can present with headache, vomiting due toformation of hydrocephalus. All these symptoms are usually due to focal compression of the cerebellum or brain stem and increased intracranial pressure.

Posterior cranial fossa tumors in children differ fromadults in their clinical presentation, behavior, 
management and prognosis. Astrocytoma and PNET of same histologicalgrade show a relatively good prognosis in children than inadults. ${ }^{4}$

The overall prognosis of patients with medulloblastoma

Are relatively improved due to radiotherepy and chemotherapy.Five year survival rate is seen in $80 \%$ of patientswhen tumor is localized to posterior cranial fossa at time ofdiagnosis. ${ }^{5}$

Cushing was probably the first to report a large series of posterior fossa tumors. He published information about 61 patients with Cerebellar Medulloblastoma with mostly fatal outcome. ${ }^{6}$

In cases of pilocytic astrocytoma, complete resectionis possible when the tumor is of small size. When these tumors become in bigger size and involve the deep brain tissue, prognosis is less favorable. ${ }^{7}$

Thefactors contributing to high morbidity and mortality are late presentation when thetumor has locally infiltrated and metastasized outsidethe cranial cavity and the tumor morphology. Advancement in neuroradiological diagnostic techniques helps in the detection of very small

Sized lesions which can be managed effectively. ${ }^{8}$

However, recurrences of benign lesions like Meningiomas increase the morbidity and mortality. ${ }^{9}$

Brain tumors continue to be among the top ten causes of cancer related deaths in the world. Brain tumors are the second most common pediatric solid tumors next to leukemia.

Posterior fossa tumors are more common in children than in adults. About 54- 70\% of all childhood brain tumors originate in the posterior cranial fossa. About 15-20\% of brain tumors in adults occur in the posterior fossa. ${ }^{10}$

This study is designed to determine the frequency and histological types of posterior cranial fossa tumors in children.

\section{Material and Methods}

The specimens are collected at our department during January 2017 to May 2019.

The data including age, sex, tumor site and histological diagnosis are taken. Patients more than 18 years were counted as adult age group and less than 18 year counted as pediatric age group. We include only child patients. The study comprises of 66 consecutive cases of posterior cranial fossa in children.

Neurosurgical intervention was carried out in all these cases. After surgery, specimens were sent for histopathological evaluation and microscopic diagnosis was made

Exclusion Criteria: Non-operated children were excluded from this study.

The requisition form of patients presenting with posterior fossa tumors were received from department record from January 2017 to May 2019 and the data of patients along with histopathological reports were collected and studied.

\section{Result}

During these study period total 280 cases of posterior cranial fossa lesion received. Among these patients, 214 were more than 18 year and 66 were pediatric age group (less than 18 year).Table 1 shows gender wise distribution of posterior fossa tumor in children.

\section{Table -1}

\begin{tabular}{|l|c|c|c|c|}
\hline Total Patient & Male & Percentage & Female & Percentage \\
\hline 66 & 42 & $63.63 \%$ & 24 & $36.37 \%$ \\
\hline
\end{tabular}

Final diagnosis was made by histopathological examination (Table 2) which is as follows-25 cases Medulloblastoma, 21Pilocytic astrocytoma, 3 cases of each ependymomas and Epidermoid cyst, 2 cases of each Meningioma, Glioblastoma
WHO grade 4 and abscess each, 1 case of each Schwannoma, A-V malformation, arachnoid cyst, choroid plexus papilloma, TB, ependymal cyst, AT/RT and colloid cyst. 


\section{JMSCR Vol||07||Issue ||07||Page 272-276||July}

Table 2: Incidence of posterior cranial fossa tumors in this study

\begin{tabular}{|l|c|c|}
\hline Morphological type & No. of cases & Percentage \% \\
\hline Medulloblastoma & 25 & $37.88 \%$ \\
\hline Pilocytic astrocytoma & 21 & $31.82 \%$ \\
\hline Ependymomas & 3 & $4.54 \%$ \\
\hline Epidermoid cyst & 3 & $4.54 \%$ \\
\hline GBM & 2 & $3.03 \%$ \\
\hline Meningioma & 2 & $3.03 \%$ \\
\hline Abscess & 2 & $3.03 \%$ \\
\hline Schwannoma & 1 & $1.51 \%$ \\
\hline Arachnoid cyst & 1 & $1.51 \%$ \\
\hline A-V malformation & 1 & $1.51 \%$ \\
\hline CPP & 1 & $1.51 \%$ \\
\hline Colloid cyst & 1 & $1.51 \%$ \\
\hline AT/RT & 1 & $1.51 \%$ \\
\hline TB & 1 & $1.51 \%$ \\
\hline Ependymal cyst & 1 & $1.51 \%$ \\
\hline Total & $\mathbf{6 6}$ & $\mathbf{1 0 0 \%}$ \\
\hline
\end{tabular}

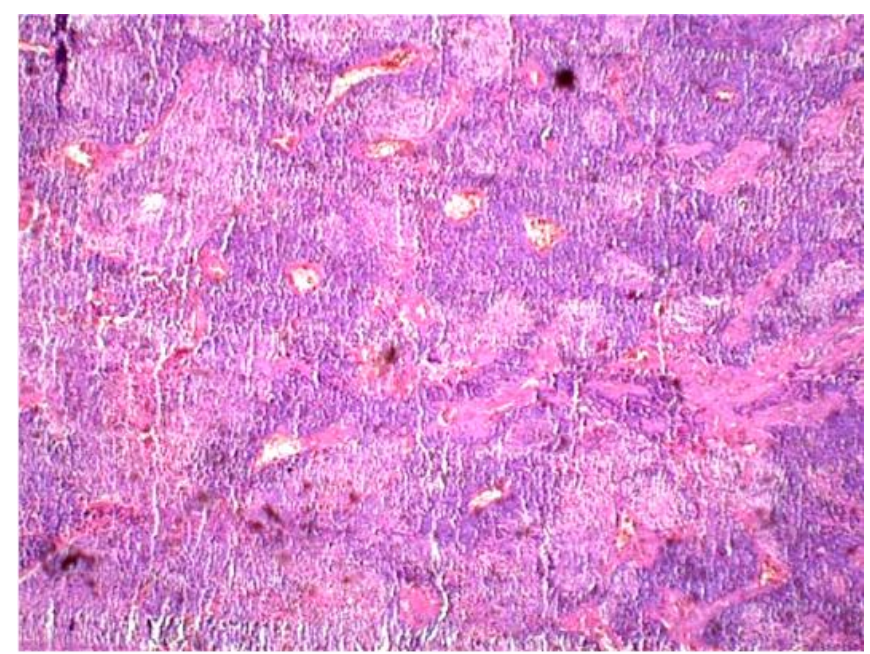

H \&E section- medulloblastoma (4X)

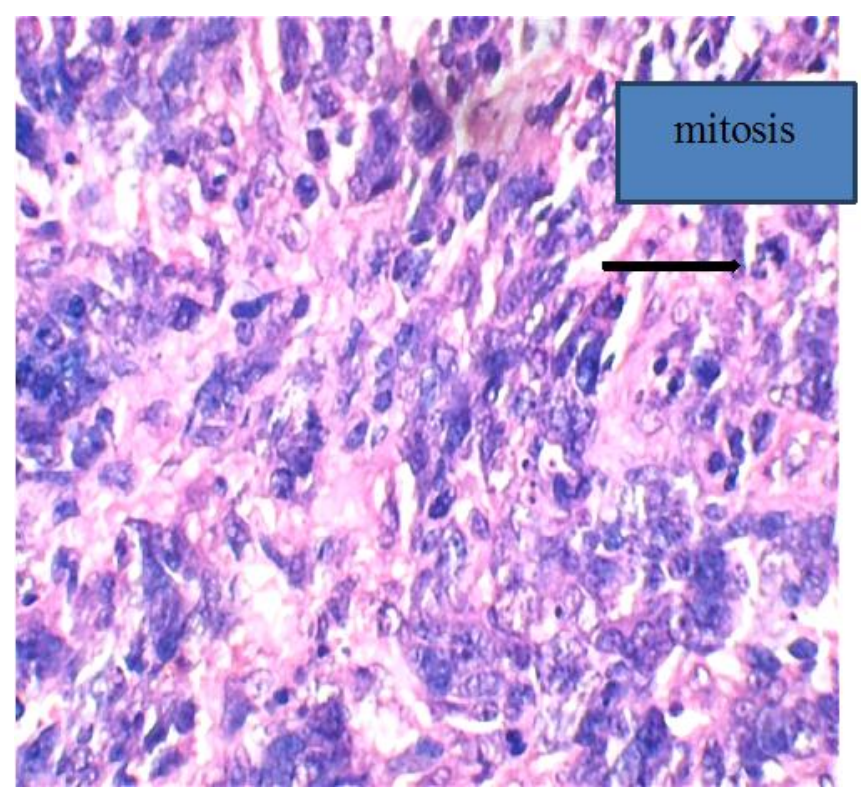

H\&E section -medulloblastoma (40X) showing mitosis

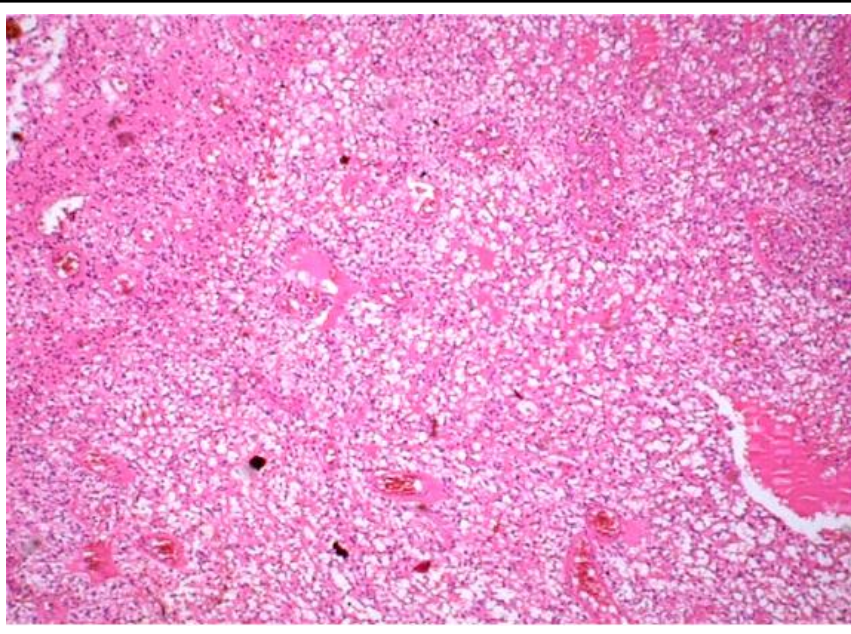

H\&E section- pilocytic astrocytoma showing glomeruloid blood vessels

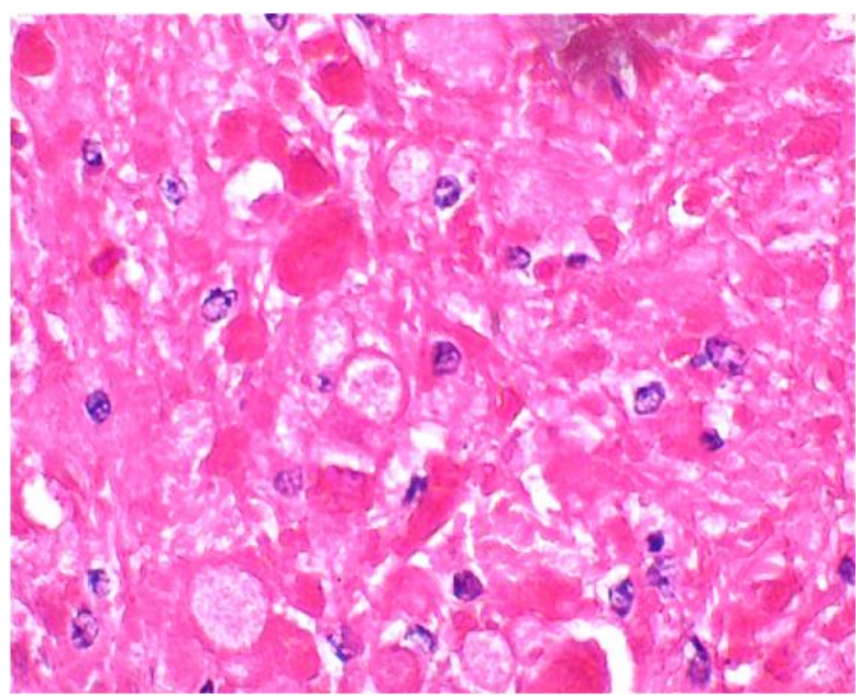

H\&E section - pilocytic astrocytoma shows EGB

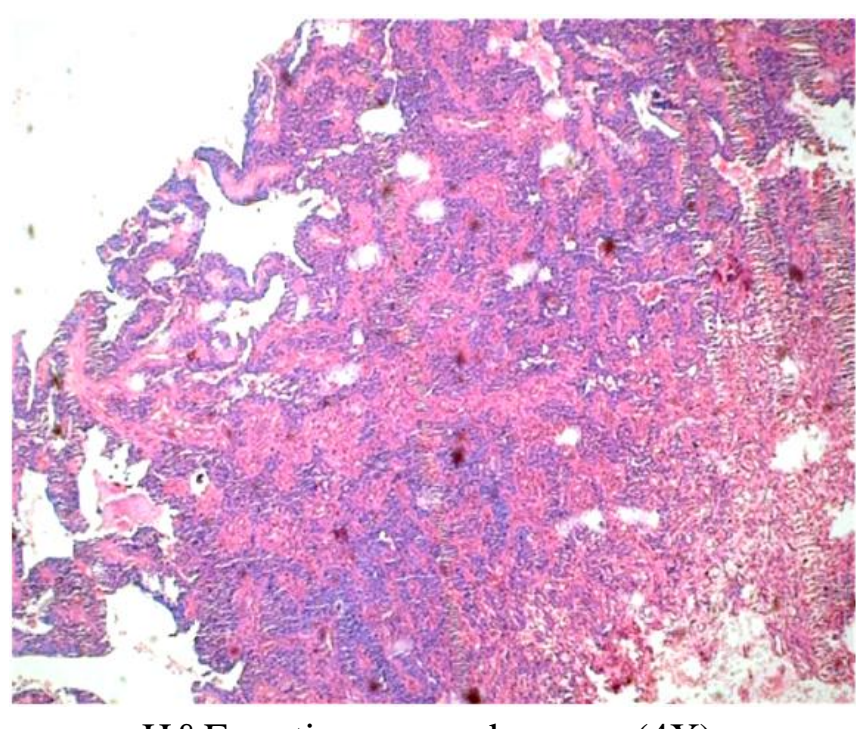

H\&E section - ependymoma (4X) 


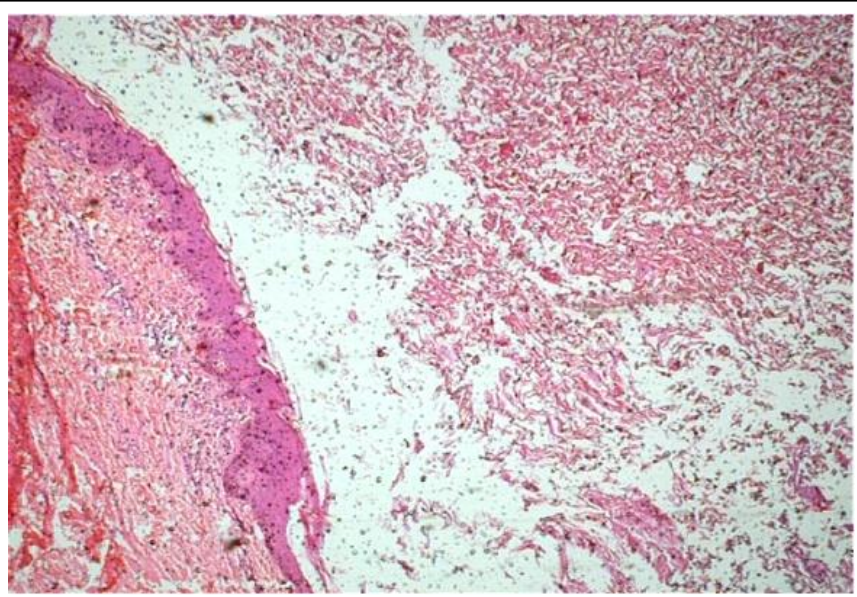

H\&E section - Epidermoid cyst

Table 3 Distribution of tumors according to the gender

\begin{tabular}{|l|c|c|c|c|c|}
\hline Histomorphological type & male & $\%$ & female & $\mathbf{\%}$ & Total \\
\hline Medulloblastoma & 19 & 28.79 & 6 & 9.09 & 25 \\
\hline Pilocytic astrocytoma & 9 & 13.63 & 12 & 18.18 & 21 \\
\hline Ependymomas & 2 & 3.03 & 1 & 1.52 & 3 \\
\hline Epidermoid cyst & 1 & 1.51 & 2 & 3.03 & 3 \\
\hline GBM4 & 2 & 3.03 & 0 & 0 & 2 \\
\hline Meningioma & 2 & 3.03 & 0 & 0 & 2 \\
\hline Abscess & 0 & 0 & 2 & 3.03 & 2 \\
\hline Schwannoma & 1 & 1.51 & 0 & 0 & 1 \\
\hline Arachnoid cyst & 1 & 1.51 & 0 & 0 & 1 \\
\hline A-V malformation & 1 & 1.51 & 0 & 0 & 1 \\
\hline CPP & 1 & 1.52 & 0 & 0 & 1 \\
\hline Colloid cyst & 1 & 1.52 & 0 & 0 & 1 \\
\hline AT/RT & 1 & 1.52 & 0 & 0 & 1 \\
\hline TB & 1 & 1.52 & 0 & 0 & 1 \\
\hline Ependymal cyst & 0 & 0 & 1 & 1.52 & 1 \\
\hline Total & $\mathbf{4 2}$ & $\mathbf{6 3 . 6 3}$ & $\mathbf{2 4}$ & $\mathbf{3 6 . 3 7}$ & $\mathbf{6 6}$ \\
\hline
\end{tabular}

Table 4 Age group wise distribution of posterior fossa tumor in children

\begin{tabular}{|l|c|c|}
\hline Age group & $0-9$ & $9-18$ \\
\hline No. of patients & 36 & 30 \\
\hline Percentage & $54.55 \%$ & 45.45 \\
\hline
\end{tabular}

\section{Discussion}

The present study was designed to determine the frequency of Posterior fossa SOL in children from January 2017to May 2019. In a series of literature, slight male predominance was seen. ${ }^{11}$ In our series, male participants are $42(\%)$ in number and female participants are $24(\%)$ in number with male predominance. The malepredominance may be due to increased number of male patients being investigated, which is a social feature in Indian society.
According to data from the Children's Hospital, Philadelphia, MBs range about 36\%, cerebellar astrocytoma in $28 \%$, brainstem glioma $9 \%$, and ependymoma in $4 \% .^{12}$

In a study from the Hospital foe Sick Cjildren in Toronto, $\mathrm{MB}$ range about $27 \%$, astrocytomas $23 \%$, brainstem glioma in $9 \%$, and ependymoma in $8 \%$ of cases.

In our series, the MB form about $37.88 \%$, pilocytic astrocytomas $31.82 \%$, ependymoma and epidermoid cyst $4.52 \%$, GBM, meningioma and abscess $3.03 \%$, schwannoma, arachnoid cyst, A-V malformation, choroid plexus papilloma, ependymal cyst, tuberculosis, colloid cyst, AT/RT $1.51 \%$ were observed.

In the literature, the case which is youngest is 6 weeks old (Rorke, 1989). ${ }^{13}$ In our series, the youngest was 5 months old. In our series, 36/66 
cases are seen below 10 years. According to Albright, most of the posterior fossa tumors occur in the age group between 1 and 10 years. ${ }^{14}$

Hydrocephalus is most commonly seen in children with posterior fossa tumors, occurring in $71-90 \%$ of pediatric patients; approximately $10-40 \%$ demonstrates persistent hydrocephalus after posterior fossa tumor resection. ${ }^{15}$

\section{Conclusion}

Medulloblastoma were most common tumor in pediatric age group. Pilocyticastrocytoma were second most common tumor with male predominance.

\section{References}

1. Cushing H. Experience with the cerebellar medulloblastoma: critical review. Acta Pathol MicrobiolImmunol Scand. 1930; 7:1-86.

2. Al-Shatoury HAH, Galhom AA, Engelhard H. Posterior fossa tumors. Emedicine Neurosurgery. 2008; Available from: https://emedicine.medscape. Com/article/249495-overview.

3. Rehman AU, Lodhi S, Murad S. Morphological pattern of posterior cranial fossa tumors. Annals.2009;15(2):51-57.

4. Rickert CH, Probst-cousin S, Gullota F. Primary intracranialneoplasm of infancy and early childhood. Childs NervSyst. 1997;13: 507-13.

5. Friedman HS, Oakes WJ, Bigner SH et al. Medulloblastoma: Tumor biological and clinical perspectives. J Neurooncol. 1991;11: 1-15.

6. Cushing H. Experience with the cerebellar medulloblastoma: Critical review. Acta Pathol Microbiol Immunol Scand. 1930; 7:1-86

7. Brown MT, Feiedman HS, Oakes WJ et al. Chemotherapy for pilocyticastrcytomas. Cancer.1993; 1: 3165-72.
8. Pollack IF. Pediatric brain tumours. Semin Surg Oncol, 1999; 16: 73-90.

9. Minimanoff RO, et al: Meningioma. Analysis of recurrence and progression following neurosurgical resection. Jneurosur. 1965; 62:18-24.

10. Al-Shatoury HAH, Galhom AA, Engelhard H. Posterior fossa tumors. Emedicine Neurosurgery. 2008. Available from: https://emedicine.medscape. com/article/249495-overview.

11. Lam S, Reddy GD, Lin Y, Jea A. Management of hydrocephalus in children with posterior fossa tumors. SurgNeurol Int. 2015;6 (Suppl 11):S346-8.

12. Sutton L, Schut L. Cerebellar astrocytomas. In: McLaurin R, Schut L, Venes, et al., editors. Pediatric Neurosurgery: Surgery of the Developing Nervous System. Philadelphia, PA: WB Saunders Co; 1989. pp. 338-46.

13. May PL, Blaser SI, Hoffman HJ, Humphreys RP, Harwood-Nash DC. Benign intrinsic tectal "tumors" in children.J Neurosurg. 1991;74:867-71.

14. Albright AL, Guthkelch AN, Packer RJ, Price RA, Rourke LB. Prognostic factors in pediatric brain-stem gliomas.J Neurosurg 1986;65:751-5.

15. Lin CT, Riva-Cambrin JK. Management of posterior fossa tumors and hydrocephalus in children: a review. Childs Nerv Syst. 2015;10:1781-9. 